\title{
INFLUENCE OF SILANE TREATMENT ON WATER ABSORPTION AND MECHANICAL PROPERTIES OF PLA/SHORT BAMBOO FIBER-REINFORCED GREEN COMPOSITES
}

\author{
SHOMA MARUYAMA, HITOSHI TAKAGI \& ANTONIO N. NAKAGAITO \\ Tokushima University, Japan
}

\begin{abstract}
Green composites (GCs) consist of biodegradable resin and natural fibers. Due to the hydrophilicity of constituents, however, GCs are usually susceptible to water absorption. When GCs absorb water, the interface between the resin and fibers peels off, resulting in the shrinkage of the fibers after drying. In this study, we investigated the influence of silane treatment on water absorption and mechanical properties of polylactic acid/short bamboo fiber (PLA/SBF) composites. The silane treatment reduced water absorption and improved the mechanical strength of PLA/SBF composites, namely the tensile strength and Young's modulus were increased by $72 \%$ and $30 \%$ respectively, compared with those of untreated PLA/SBF composites. The silane treatment also increased interfacial adhesion of resin/fiber resulting in improved water absorption rate. Thus, it is concluded that the silane treatment is effective for improving the mechanical and water-proofing performances of PLA/SBF composites.

Keywords: bamboo fiber, green composites, polylactic acid, silane treatment.
\end{abstract}

\section{INTRODUCTION}

In recent years, while industries have developed based on petroleum-based chemistry, many environmental problems such as air pollution and global warming are matters of concern. Therefore, researchers' special attention is being paid to the development of biodegradable composite materials called green composites (GCs) as alternative materials to petroleumderived plastics and composites [1]-[4]. The GC is a composite material in which biodegradable resin is reinforced with natural fibers, and it is made from various renewable resources as it is derived from natural plants. Hence, the emission of carbon dioxide generated when incinerating GCs is unchanged due to the concept of carbon neutral.

However, as a disadvantage of GCs, it is pointed out that their mechanical properties deteriorate in underwater environment [5]. The GCs swell when GCs absorb water, and after subsequent drying, the fiber shrinkage occurs, and the interfaces between the resin and the fiber are often peeled off. Thus, it is considered that the mechanical strength of GCs decreases because natural fibers do not fulfill the reinforcing function. It is an urgent matter to improve the interfacial adhesion between resin and fibers during water absorption.

An effective method for improving the interfacial adhesion between resin and fibers of GCs is silane coupling treatment. The silane treatment generally refers to a surface treatment using a silane coupling agent as a bonding aid to chemically bond inorganic substances to organic substances. It has been confirmed that when silane treatment is applied to GCs made with polylactic acid (PLA) and wheat husks, the mechanical strength of the composites has been improved and their water absorption has been reduced [6]. It is speculated from these results that by applying silane treatment to GCs, the interfacial adhesion strength between resin and fibers can be improved in other GCs, leading to improvement of mechanical strength and suppression of water absorption.

In this study, therefore, we fabricated GCs using PLA which is one of the widely used biodegradable resins and high strength bamboo fiber among natural fibers. The effects of 
silane treatment on the mechanical properties and water absorption of the PLA/bamboo fiberreinforced GCs were investigated.

\section{EXPERIMENTAL METHODS}

\subsection{Fabrication method of composite samples}

In this research, PLA/short bamboo fiber (SBF) composites in which SBFs are randomly oriented in the PLA matrix were prepared by using a hot-pressing method. First, long bamboo fibers of 300-450 mm extracted by steam-explosion treatment [7] of raw bamboo were cut into short fibers of about $30 \mathrm{~mm}$. These short fibers were subjected to alkali treatment with an aqueous $\mathrm{NaOH}$ solution ( $5 \mathrm{wt} . \% \mathrm{NaOH}$ ) for $30 \mathrm{~min}$ and blender treatment was then carried out for 20 min to prepare SBFs.

Silane treatment was performed on SBFs. In this study, two kinds of silane agents, 3-aminopropyltrimethoxysilane (APMS) and 3-glycidyloxypropyltrimethoxysilane (GPMS), were used. A silane coupling agent in an amount of $1 \mathrm{wt} . \%$ based on the fiber weight was added dropwise in a solution prepared by mixing methanol and distilled water at a ratio of 1:1. A silane solution was prepared by adjusting the $\mathrm{pH}$ of the solution to 4.0 by adding acetic acid. After that, the SBFs were immersed in the silane solution for $1 \mathrm{~h}$. The treated SBFs were dried at room temperature for 2 days and further dried with a constant temperature drier at $50^{\circ} \mathrm{C}$ for $24 \mathrm{~h}$.

After drying, the silane-treated SBFs and dispersion-type PLA resin (PL-2000, Miyoshi Oil and Fat Co., Ltd., Japan) were mixed to be 40wt.\% fiber loading and then treated for $4 \mathrm{~h}$ in a vacuum defoaming stirrer. The mixed sample was poured into a rectangular container and then dried at $50^{\circ} \mathrm{C}$ for 2 days to prepare composite preform sheets. Thereafter, the dried preforms were cut into strips having a size of $10 \times 100 \mathrm{~mm}$ with a table-top circular saw and dried at $105^{\circ} \mathrm{C}$ for $1 \mathrm{~h}$, then hot pressed at $190^{\circ} \mathrm{C}, 5 \mathrm{MPa}, 5 \mathrm{~min}$ to prepare PLA/SBF composite samples. A detailed preparation method is also mentioned elsewhere [8].

\subsection{Mechanical and fractographical characterization of composite samples}

All the tensile tests were conducted at a tensile speed of $1.0 \mathrm{~mm} / \mathrm{min}$ on an Instron material testing machine (Model 5567, USA). The shape of the specimen was $10 \mathrm{~mm}$ wide and $100 \mathrm{~mm}$ long, and the gauge length was $30 \mathrm{~mm}$. Both the tensile strength and Young's modulus were evaluated from the stress-strain curves obtained.

The fractographical morphology of the PLA/SBF composites and their interfaces between PLA and bamboo fibers was examined by a scanning electron microscope (SEM: S-4700, Hitachi Ltd., Japan). All samples were sputter-coated with gold/platinum prior to the SEM observation.

\subsection{Water absorption and drying test of composite samples}

The water absorption rate of the PLA/SBF composites was evaluated according to JIS K 7209 (2000) standard. Five PLA/SBF composite samples were dried at $105^{\circ} \mathrm{C}$ for $1 \mathrm{~h}$, then soaked in distilled water at room temperature for $5,25,100$, and $250 \mathrm{~h}$. After immersion in water, the samples were taken out, their surface water was entirely wiped off with a cloth, and the weight of the wet state sample was measured. Thereafter, drying again at $105^{\circ} \mathrm{C}$ for $1 \mathrm{~h}$, and then weight gain rate, $M_{g}$ and weight loss rate, $M_{l}$ of the sample were calculated from the following equations: 


$$
M_{g}=\frac{W_{w}-W_{d}}{W_{0}} \times 100
$$

and

$$
M_{l}=\frac{W_{0}-W_{d}}{W_{0}} \times 100,
$$

where $W_{0}$ is the weight of the dry sample before water absorption, $W_{w}$ is the weight of the wet sample, and $W_{d}$ is the weight of the re-dried sample after water absorption.

The tensile properties of the PLA/SBF composites after water absorption were evaluated by carrying out the tensile tests in the manner as described in Section 2.2. In addition, the fracture surface of the test specimen was also examined by SEM.

\section{RESULTS AND DISCUSSION}

\subsection{Effect of silane treatment on mechanical properties of PLA/SBF composites}

Figs 1 and 2 show the mechanical properties of neat PLA, PLA/SBF composites, alkalitreated PLA/SBF composites, and silane-treated PLA/SBF composites (APMS and GPMS). The PLA/SBF composites without any surface treatment have higher strength and higher Young's modulus than neat PLA. The strength and Young's modulus of the alkali-treated PLA/SBF composites are higher than those of untreated PLA/SBF composites. The highest mechanical properties are obtained in the silane-treated PLA/SBF composites. The tensile strength of the silane-treated sample was $80.3 \mathrm{MPa}$ and Young's modulus was 5.2 GPa. Compared with the untreated sample, the tensile strength and Young's modulus are increased by $72 \%$ and $30 \%$, respectively. The effect of these surface treatment, the interfacial bonding was increased and the stress transmission ability between the fiber and matrix was improved, which resulted in an improvement in mechanical properties.

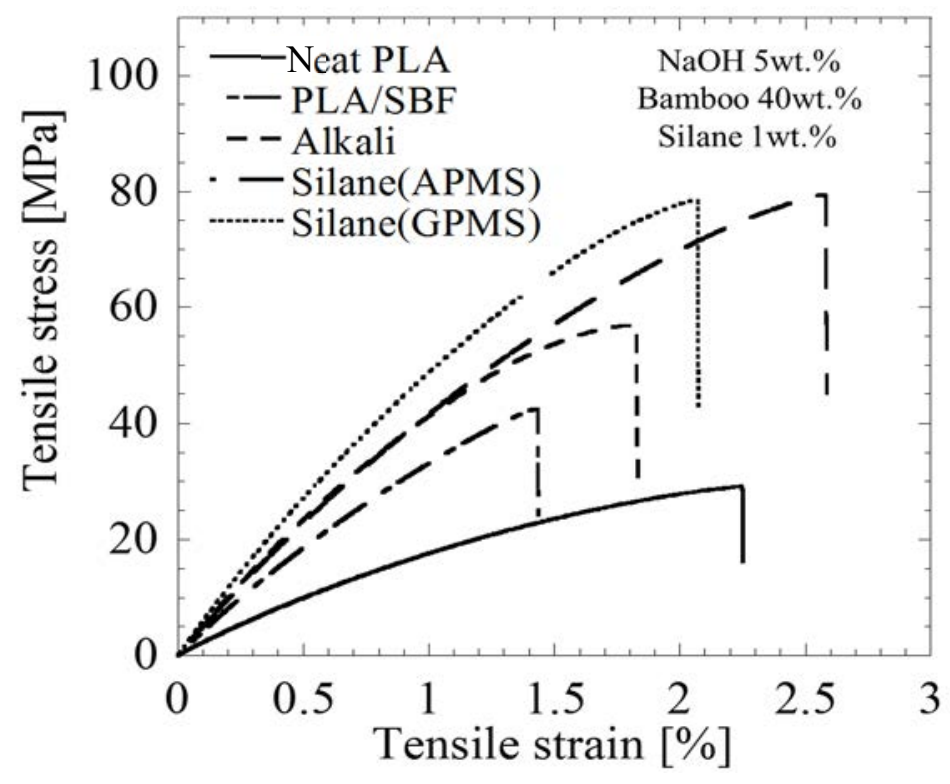

Figure 1: Typical stress-strain curves of surface-treated and untreated PLA/SBF composites. 


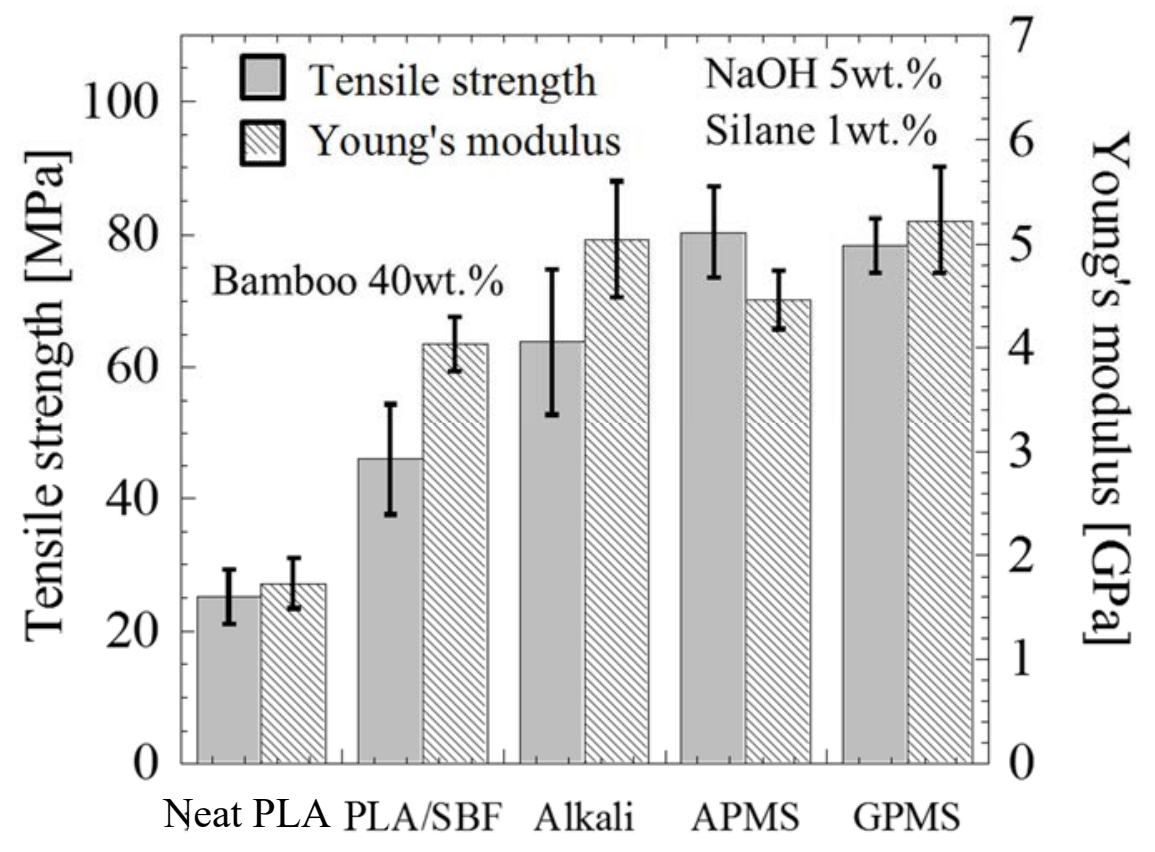

Figure 2: Effect of surface treatment on tensile properties of PLA/SBF composites.

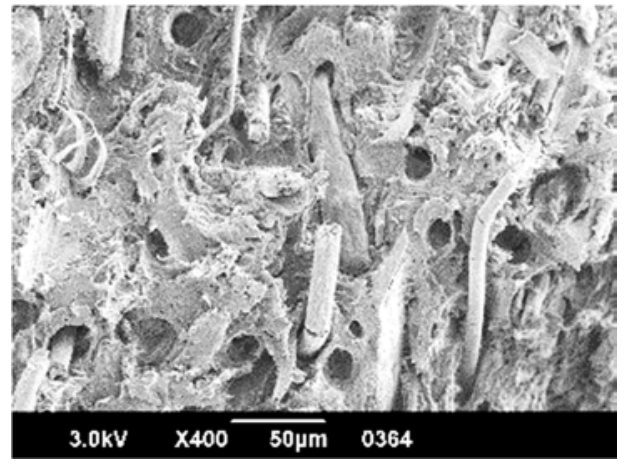

(a)

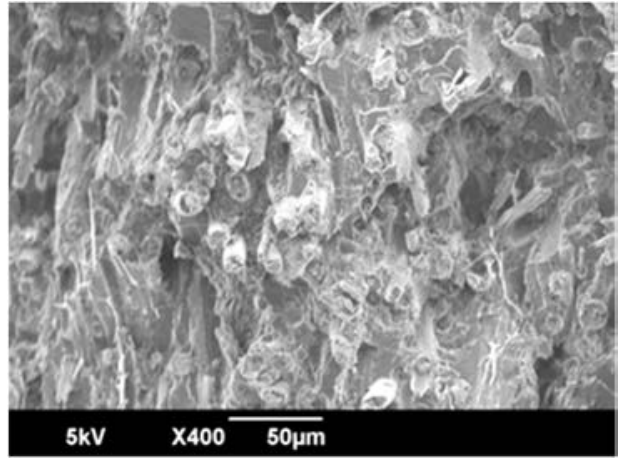

(b)

Figure 3: SEM images of fracture surface. (a) Untreated PLA/SBF composites; and (b) Silane (GPMS)-treated PLA/SBF composites.

The SEM photomicrographs of the untreated PLA/SBF composites and silane-treated PLA/SBF composites are indicated in Fig. 3, respectively. Many pull-out cavities are found on the fracture surface of the untreated PLA/SBF composites. However, the fracture surface of the silane-treated PLA/SBF composites has few traces of pull-out and most of the bamboo fibers are covered with matrix PLA resin. It is suggested from these results that the silane treatment improves the interfacial adhesion between the resin and the fibers and that the 
mechanical properties of the PLA/SBF composites are improved. A similar increase in mechanical properties related to the alkali and silane treatment was reported elsewhere [9].

\subsection{Effect of silane treatment on absorption behavior of PLA/SBF composites}

Figs 4 and 5 show the results on how the water absorptivity and mechanical properties of the silane (APMS)-treated PLA/SBF composites are affected when the composites are immersed in water for up to $250 \mathrm{~h}$.

The water absorption rate and the weight loss rate of each PLA/SBF composite sample after immersion in water for $250 \mathrm{~h}$ are shown in Fig. 4. The water absorption rate of the silane-treated PLA/SBF composites shows $17.6 \%$. It decreased by about 4.8 points compared with that of alkali-treated composites. As for the weight loss rate, it is about 0.3 points larger than that of neat PLA, however, it is seen that it decreases compared with other composites containing bamboo fibers. From these results, it is suggested that the water absorption was improved because water penetration in the silane-treated PLA/SBF composites was prevented by improving the interfacial adhesion between the PLA matrix and bamboo fibers.

Fig. 5 shows the variation in tensile strength after immersion in water. It was found that after water immersion for $250 \mathrm{~h}$, the tensile strength of all PLA/SBF composites decreased. In the untreated PLA/SBF composites, the tensile strength decreased by $55 \%$, however, in the silane (APMS)-treated composites the reduction rate of the tensile strength was $45 \%$, thus the reduction rate of about 10 points could be improved. It is considered from this result that the decrease in tensile strength could be suppressed because the interfacial adhesion between resin matrix and fiber was improved by silane treatment.

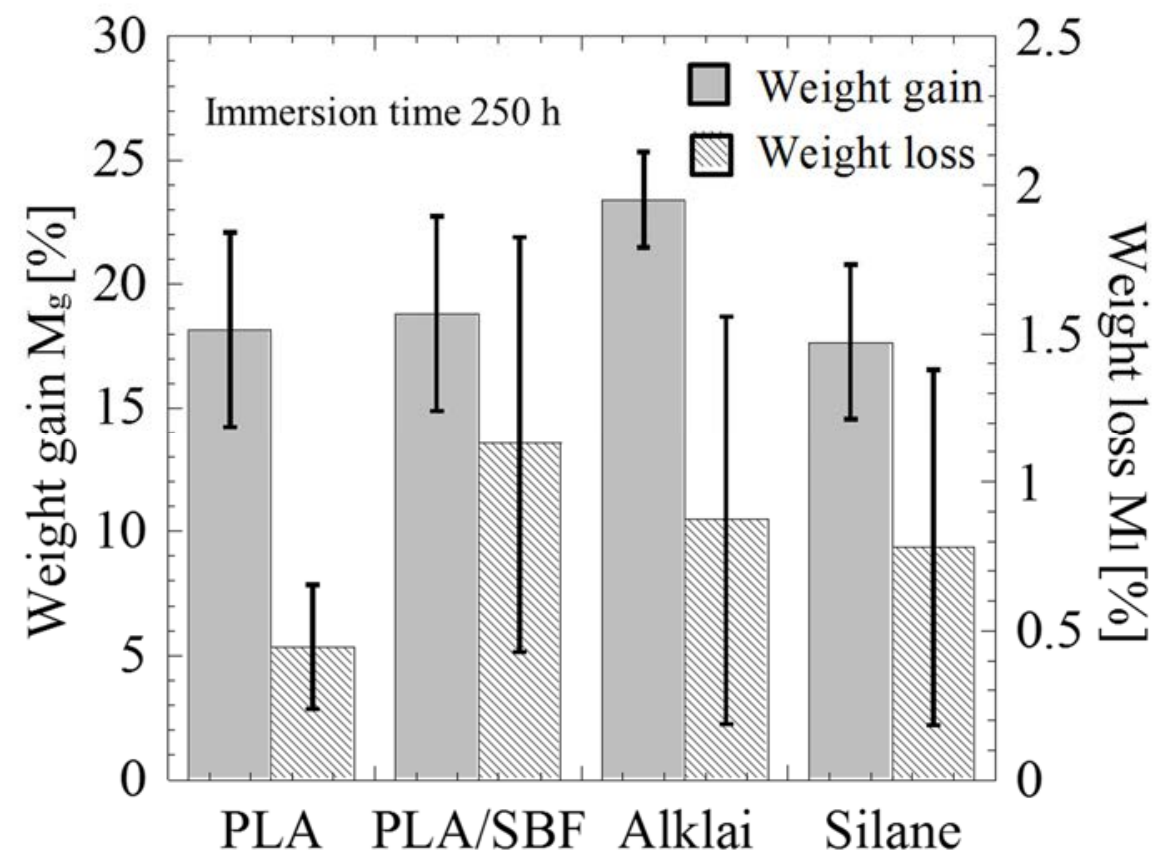

Figure 4: Comparison of weight gain and weight loss of treated and untreated PLA/SBF composites after immersion of $250 \mathrm{~h}$. 


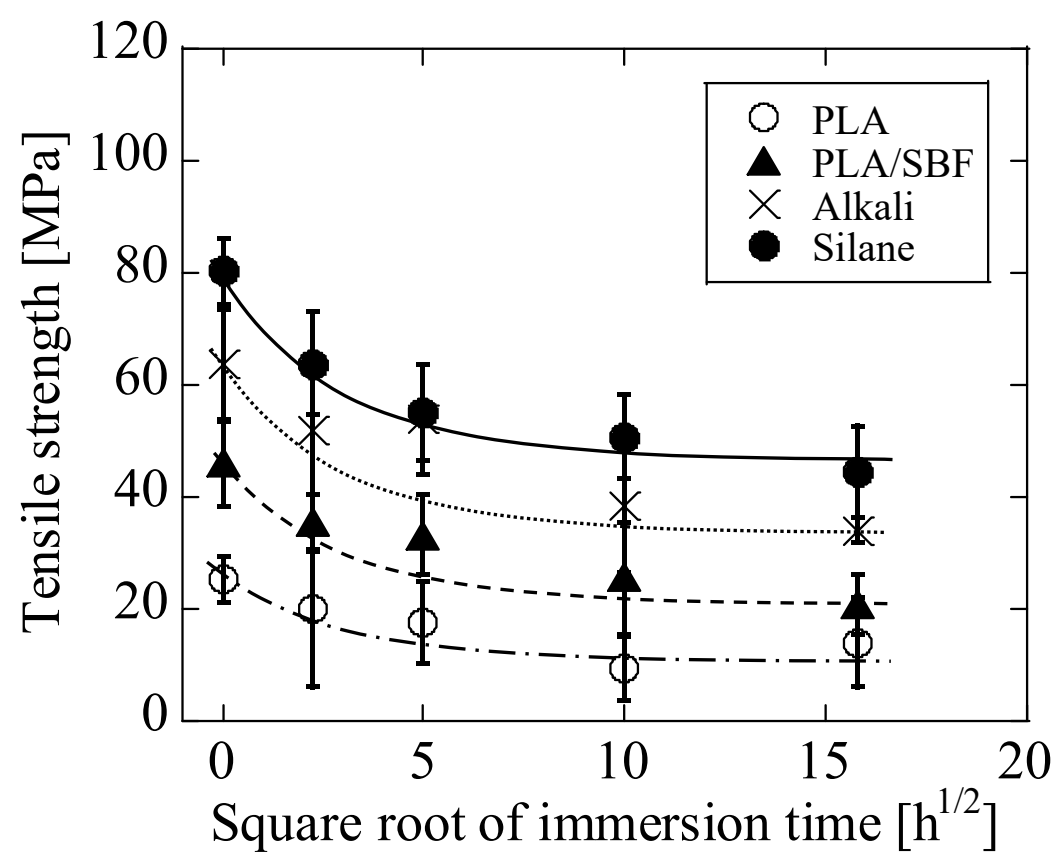

Figure 5: The relationship between tensile strength of PLA/SBF composites and immersion time.

\section{CONCLUSIONS}

In this study, we fabricated PLA/SBF composites and examined the effects of silane treatment on mechanical properties and water absorption of the composites. In conclusion, the present results demonstrate that silane treatment is useful as a method for improving the resin/ fiber interfacial adhesion, the water absorption, and mechanical properties of the PLA/SBF composites.

\section{ACKNOWLEDGEMENT}

We acknowledge financial support from JSPS, KAKENHI project number $16 \mathrm{H} 01790$.

\section{REFERENCES}

[1] Liu, K., Takagi, H., Osugi R. \& Yang, Z.M., Effect of physicochemical structure of natural fiber on transverse thermal conductivity of unidirectional abaca/bamboo fiber composites. Composites Part A, 43(8), pp. 1234-1241, 2012.

[2] Liu, K., Yang, Z. M. \& Takagi, H., Anisotropic thermal conductivity of unidirectional natural abaca fiber composites as a function of lumen and cell wall structure. Composite Structures, 108, 987-991, 2014.

[3] Katogi, H. \& Takemura, K., The effect of soil on the biodegradable behavior of green composites under various environmental (ambient) temperature. WIT Transactions on Engineering Sciences, vol. 90, pp. 47-55, 2015.

[4] Sukmawan, R., Takagi, H. \& Nakagaito, A.N., Strength evaluation of cross-ply green composite laminates reinforced by bamboo fiber. Composites Part B, 84, pp. 9-12, 2015. 
[5] Takemura, K., Takai, S. \& Katogi, H., Effects of microfibrillated cellulose addition and water absorption on mechanical properties of jute/PLA composites. WIT Transactions on The Built Environment, vol. 124, pp. 387-394, 2012.

[6] Asumani, O.M.L., Reid, R.G. \& Paskaramoorthy, R., The effects of alkali-silane treatment on the tensile and flexural properties of short fibre non-woven kenaf reinforced polypropylene composites. Composites: Part A, 43(9), pp. 1431-1440, 2012.

[7] Takagi, H., Kako, S., Kusano K. \& Ousaka, A., Thermal conductivity of PLA-bamboo fiber composites. Advanced Composite Materials, 16(4), pp. 377-384, 2012.

[8] Maruyama, S., Takagi, H., Nakamura, Y., Nakagaito, A.N. \& Sasaki, C., Influence of alkali treatment on mechanical properties of poly lactic acid bamboo fiber green composites. Advanced Materials Research, 1110, pp. 56-59, 2015.

[9] Cai, M., Takagi, H., Nakagaito, A.N., Li, Y. \& Waterhouse, G.I.N., Effect of alkali treatment on interfacial bonding in abaca fiber-reinforced composites. Composites Part A, 90, pp. 589-597, 2016. 